\title{
Corrigendum: SCD1 Confers Temozolomide Resistance to Human Glioma Cells Via the Akt/GSK3 $\beta /$ $\beta$-Catenin Signaling Axis
}

OPEN ACCESS

Edited and reviewed by: Julie Gavard,

Institut National de la Santé et de la

Recherche Médicale (INSERM),

France

*Correspondence: Zhicheng Gong

gongzhicheng@csu.edu.cn

tThese authors have contributed equally to this work

Specialty section: This article was submitted to Pharmacology of Anti-Cancer Drugs,

a section of the journal

Frontiers in Pharmacology

Received: 30 September 2019

Accepted: 28 October 2019

Published: 15 November 2019

Citation:

Dai S, Yan Y, Xu Z, Zeng S, Qian L,

Huo L, Li X, Sun L and Gong $Z$ (2019) Corrigendum: SCD1 Confers Temozolomide Resistance to Human Glioma Cells Via the Akt/GSK3 $\beta / \beta$ Catenin Signaling Axis.

Front. Pharmacol. 10:1358. doi: 10.3389/fphar.2019.01358

\section{Shuang Dai ${ }^{1,2,3 \dagger}$, Yuanliang Yan ${ }^{1,3 \dagger}$, Zhijie X ${ }^{1,3,4}$, Shuangshuang Zeng ${ }^{1,3}$, Long Qian ${ }^{1,3}$,} Lei Huo ${ }^{5}$, Xuejun $L^{5}{ }^{5}$, Lunquan Sun ${ }^{6}$ and Zhicheng Gong ${ }^{1,3 *}$

\begin{abstract}
${ }^{1}$ Department of Pharmacy, Xiangya Hospital, Central South University, Changsha, China, ${ }^{2}$ School of Pharmaceutical Sciences, Central South University, Changsha, China, ${ }^{3}$ National Clinical Research Center for Geriatric Disorders, Xiangya Hospital, Central South University, Changsha, China, ${ }^{4}$ Department of Pathology, Xiangya Hospital, Central South University, Changsha, China, ${ }^{5}$ Department of Neurosurgery, Xiangya Hospital, Central South University, Changsha, China, ${ }^{6}$ Center for Molecular Medicine, Key Laboratory for Molecular Radiation Oncology of Hunan Province, Xiangya Hospital, Central South University, Changsha, China
\end{abstract}

Keywords: glioblastomas, temozolomide, resistance, SCD1, Akt signaling

\section{A Corrigendum on}

SCD1 Confers Temozolomide Resistance to Human Glioma Cells via the Akt/GSK3 $\beta / \beta$-Catenin Signaling Axis.

By Dai S, Yan Y, Xu Z, Zeng S, Qian L, Huo L, Li X, Sun L and Gong Z (2018) Front. Pharmacol. 8:960. doi: 10.3389/fphar.2017.00960

In the original article, there was a mistake in Figure 6D as published. The final submission for the SCD1 bands in Figure 6D was inadvertently truncated too short. The corrected Figure 6D appears below.

The authors apologize for this error and state that this does not change the scientific conclusions of the article in any way. The original article has been updated.

Copyright $\odot 2019$ Dai, Yan, Xu, Zeng, Qian, Huo, Li, Sun and Gong. This is an open-access article distributed under the terms of the Creative Commons Attribution License (CC BY). The use, distribution or reproduction in other forums is permitted, provided the original author(s) and the copyright owner(s) are credited and that the original publication in this journal is cited, in accordance with accepted academic practice. No use, distribution or reproduction is permitted which does not comply with these terms. 


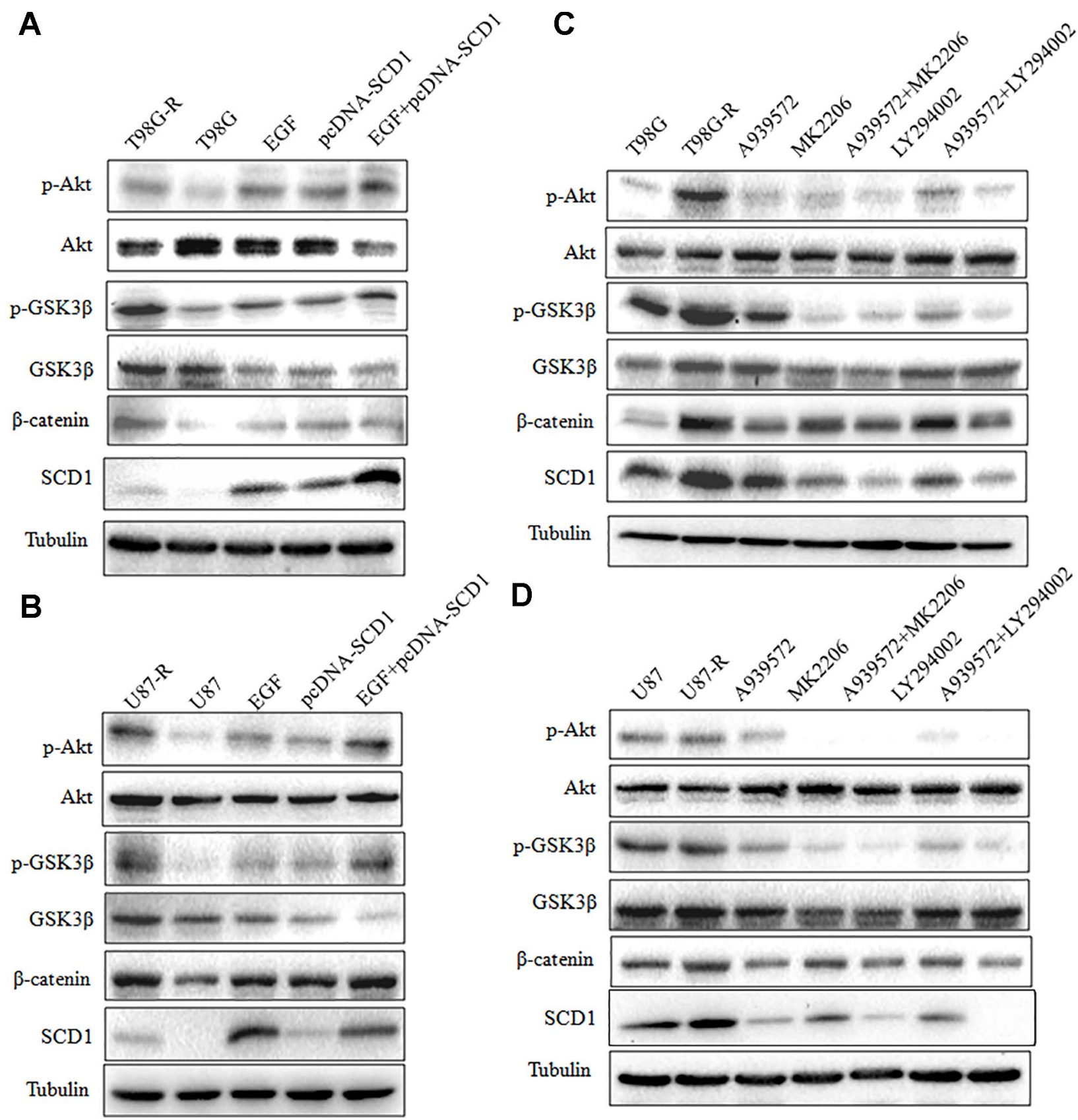

FIGURE 6 | Modulation of Akt activation level has a feedback effect on the SCD1 level. Western blot for phospho-Akt (Ser-473), Akt, phospho-GSK3b (Ser9),GSK3 $\beta$, $\beta$-catenin, and SCD1 in T98G and U87 cells treated with pcDNA3.1, pcDNA-SCD1, EGF or pcDNA-SCD1 plus EGF (A, B), or T98G-R and U87-R treated with DMSO, A939572, MK2206, A939572 plus MK2206, LY294002 and A939572 plus LY294002 (C, D). All western blots are representative of results from at least three independent experiments. And $\alpha$-Tubulin was used as the internal control. 